\title{
Denominações para o brinquedo "balanço" no estado de São Paulo: análise diatópica e léxico- semântica
}

DOI: http://dx.doi.org/10.21165/el.v49i2.2717

\section{Beatriz Aparecida Alencar ${ }^{1}$}

\section{Resumo}

Considerando a relevância dos jogos e diversões infantis para a sociedade e a relação existente entre o modo de executar e de nomear próprio de cada grupo social, este estudo busca analisar as denominações do conceito expresso na pergunta 166/QSL do Projeto Atlas Linguístico do Brasil (ALiB): "como se chama uma tábua pendurada por meio de cordas, onde uma criança se senta e se move para frente e para trás?" (COMITÊ NACIONAL DO PROJETO ALIB, 2001, p. 35), examinando dados geolinguísticos de 47 localidades da rede de pontos do Projeto ALiB no estado de São Paulo (SP) e cidades limítrofes. O trabalho pautou-se em pressupostos teóricos da Dialetologia (CARDOSO, 2010), da Lexicologia (BIDERMAN, 1998), da Semântica (COSERIU, 1979) e da Etnolinguística (SAPIR, 1969), buscando demonstrar a inter-relação entre léxico, cultura e história social do estado de São Paulo.

Palavras-chave: dialetologia; estado de São Paulo; jogos e diversões infantis; balanço; Projeto ALiB.

1 Instituto Federal de Mato Grosso do Sul (IFMS), Campo Grande, Mato Grosso do Sul, Brasil; bia83_12@hotmail.com; https://orcid.org/0000-0002-3559-6559 


\section{Denominaciones para el juguete "columpio" en el estado de São Paulo: análisis diatópica y léxico-semántica}

\section{Resumen}

Considerando la relevancia de los juguetes y diversiones infantiles en la sociedad y la relación entre la forma de ejecutar y nombrar propia de cada grupo, este estudio busca analizar las denominaciones que nombran el concepto expreso en la pregunta 166/ QSL del Proyecto Atlas Linguístico do Brasil (ALiB): "Cómo se llama una tabla colgada en cuerdas en que un niño se sienta y se mueve para frente y para tras (al vaivén)?" (COMITÉ NACIONAL DO PROJETO ALIB, 2001, p. 35), examinando dados geolingüísticos de 47 localidades de la red de puntos del Proyecto ALiB en el estado de São Paulo (SP) y ciudades limítrofes. El trabajo se guio en los parámetros de la Dialectología (CARDOSO, 2010), Lexicología (BIDERMAN, 1998), Semántica (COSERIU, 1979) y Etnolingüística (SAPIR,1969) con objetivo de demostrar la interrelación entre léxico, cultura e historia social del estado de São Paulo.

Palabras clave: dialectología; estado de São Paulo; juguetes y diversiones infantiles; columpio; Proyecto ALiB.

\section{Primeiras palavras}

Os entretenimentos infantis permeiam o imaginário de crianças e adultos e devido a sua relevância para a cultura de uma população acabam por influenciar o comportamento linguístico de um grupo social, sobretudo no aspecto lexical, pois "[...] o léxico de uma língua constitui uma forma de registrar o conhecimento do universo" (BIDERMAN, 1998, p. 91).

Tendo em vista a importância do léxico em questão e a sua indissociável relação com a sociedade que a utiliza, este trabalho analisa, em termos diatópico e léxico-semântico, as denominações para o conceito expresso na pergunta 166, do Questionário Semânticolexical do Projeto ALiB (Atlas Linguístico do Brasil), área semântica dos jogos e diversões infantis: "uma tábua, pendurada por meio de cordas, onde uma criança se senta e se move para frente e para trás?" (COMITÊ NACIONAL DO PROJETO ALiB, 2001, p. 35), coletadas pelo Projeto ALiB nas 37 localidades que integram a rede de pontos desse projeto no interior do estado de São Paulo e em 10 pontos de inquéritos situados na fronteira paulista, considerados como área de controle neste estudo (uma localidade no MS; duas no RJ; três no PR e quatro em MG). Desse modo, o corpus para este trabalho foi constituído pelas respostas fornecidas por 188 informantes, quatro pessoas de cada uma das localidades investigadas, de ambos os sexos, de duas faixas etárias (I: 18-30 e II: 50-65 anos), com ensino fundamental incompleto. Os dados obtidos são discutidos no trabalho considerando: i) a análise diatópica das denominações produtivas, de acordo 
com os dados quantitativos e a distribuição das variantes na área de pesquisa (estado de SP/área de controle); ii) o exame das variáveis sociais (diassexual e diageracional), com destaque para as duas denominações mais produtivas e ainda caberá a análise léxicosemântica das denominações mais produtivas e possíveis motivações de seu uso.

Para tanto, o estudo pauta-se em fundamentos teóricos da Dialetologia (CARDOSO, 2010), da Lexicologia (BIDERMAN, 1998), da Semântica (COSERIU, 1979) e da Etnolinguística (SAPIR, 1969). Este estudo tem, pois, como objetivos: i) evidenciar, com base nos dados lexicais relacionados à pergunta assinalada, a indissociável relação entre léxico, cultura e história social, no caso a do estado de São Paulo; ii) delinear possíveis áreas dialetais de uso das variantes lexicais documentadas; iii) comparar os dados com outros estudos já concluídos com base em dados das localidades assinaladas ou adjacentes, como o ALPR II (ALTINO, 2007); o ALTOSP (SANTOS-IKEUCHI, 2014) e o estudo sobre o falar fluminense (SANTOS, 2016), com o objetivo de examinar a produtividade das denominações em áreas próximas ao estado de São Paulo.

Quanto ao brinquedo balanço, nota-se que a sua utilização, na atualidade, é bastante frequente pelas pessoas, visto que esse tipo de entretenimento é comum em parques públicos, residências e áreas de lazer para as crianças. Além da sua presença no cotidiano, observou-se, no decorrer da análise, que a pergunta foi bastante produtiva, consequentemente, registrando um baixo número de abstenção.

A questão selecionada para estudo obteve 204 ocorrências e motivou o registro de um grande número de denominações. Para fins de análise, foram realizados alguns agrupamentos, que, em sua maioria, obedeceram a critérios lexicais, fonéticos, morfológicos e associativos. Como resultado, seis variantes lexicais foram agrupadas: balanço, balango, balançador, gangorra, rede, beló. Dentre elas, balanço foi a designação mais produtiva para nomear o brinquedo em questão. No Quadro 1, a seguir, apresentamse as variantes lexicais e respectivos agrupamentos. 
Quadro 1. Agrupamentos de variantes lexicais para "uma tábua, pendurada por meio de cordas, onde uma criança se senta e se move para frente e para trás"

(Banco de Dados do Projeto ALiB, 2018)

\begin{tabular}{|c|c|}
\hline Variantes lexicais & Agrupamentos \\
\hline Balanço & Balanço, balança, balancê, balancinho \\
\hline Balango & Balango \\
\hline Balançador & Balançador, brincar de balançar \\
\hline Gangorra & Rede \\
\hline Rede & Beló \\
\hline Beló & Barquinha, cangem, cavalinho \\
\hline $\begin{array}{c}\text { Outras denominações com ocorrências } \\
\text { únicas }\end{array}$ \\
\hline
\end{tabular}

Fonte: Elaboração própria

De acordo com o quadro 1, ainda foram reunidas três respostas como ocorrências únicas (barquinha, cangem, cavalinho). Na continuação, são discutidas as informações sobre a produtividade das variantes cartografadas levando em conta as áreas investigadas como blocos (estado de São Paulo e área de controle).

\section{Balanço: produtividade das variantes cartografadas}

Verificando a totalidade dos pontos de inquérito, nota-se a predominância de balanço com 161 ocorrências. Considerando apenas o interior do estado de São Paulo, a variante balanço foi a mais produtiva com $79 \%$ das ocorrências. Na sequência, o gráfico 1 indica as denominações analisadas e seus respectivos percentuais de ocorrência, conforme as respostas válidas para a questão 166/QSL/ALiB nos pontos do interior do estado de São Paulo. 
Gráfico 1. Denominações para "balanço" e respectivo índice de ocorrência no interior de São Paulo

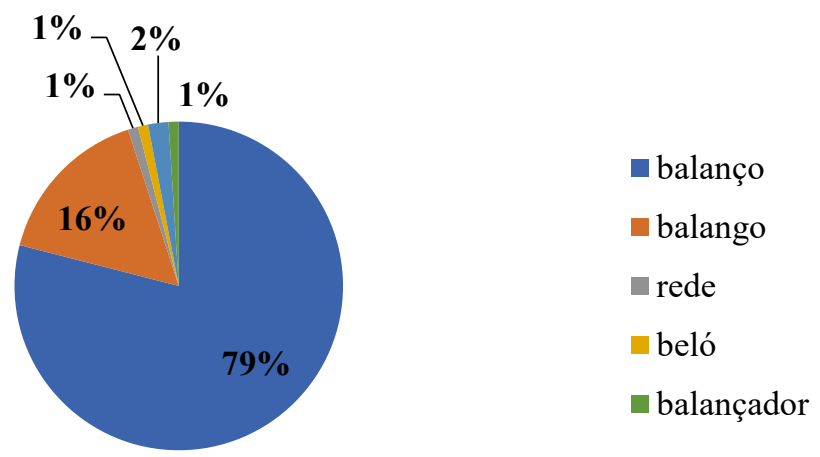

Fonte: Elaboração da autora com base no Banco de Dados do Projeto ALiB (2018)

Os dados do gráfico 1 evidenciam a expressiva produtividade da unidade lexical balanço no interior de São Paulo com 125 ocorrências (79\%), seguida com larga diferença de balango (16\%) com 25 ocorrências. Quanto às demais variantes, os valores percentuais são bastante próximos e igualmente baixos.

Informa-se queos maiores percentuais deocorrências estão distribuídos nas mesorregiões de Itapetininga (balanço, rede e beló), de São José do Rio Preto (balango) e no Litoral Sul Paulista (balançador). Já se tratando da área de controle, verificou-se o registro de apenas três denominações: balanço, balango e gangorra, como atesta o gráfico 2.

Gráfico 2. Produtividade das denominações para "balanço" no conjunto da área de controle

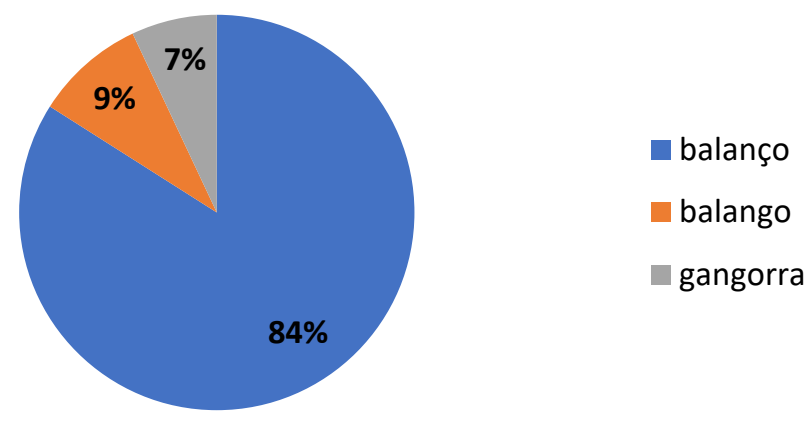

Fonte: Elaboração da autora com base no Banco de Dados do Projeto ALiB (2018) 
As informações do Gráfico 2 comprovam que a unidade lexical balanço segue como a variante mais produtiva na totalidade das respostas da área de controle com 36 ocorrências. Observando os dados específicos de cada estado da área de controle (gráfico 3), percebem-se dois comportamentos entre os estados, já que, em algumas unidades federativas, os informantes indicaram mais de uma denominação como resposta para a questão 166/QSL/ALiB.

Gráfico 3. Denominações para "uma tábua pendurada por meio de cordas, onde uma criança se senta e se move para frente e para trás"

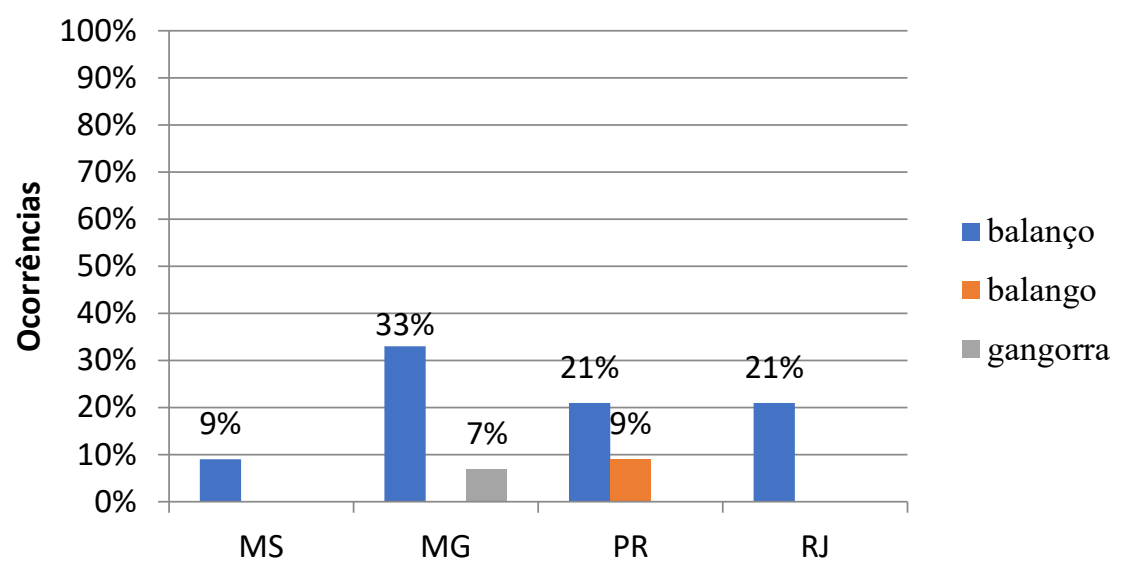

Fonte: Elaboração da autora com base no Banco de Dados do Projeto ALiB (2018)

De modo geral, observa-se que, em Mato Grosso do Sul e Rio de Janeiro, balanço é a única resposta fornecida pelos informantes, enquanto no Paraná, balanço concorre com balango e, em Minas Gerais, com gangorra. Tendo em vista essa subdivisão e a melhor visualização dos dados, é possível verificar as duas cartas lexicais produzidas acerca dessa pergunta (Anexo 1 - carta 13a: Denominações para balanço/São Paulo - e Anexo 2 - carta 13b: Denominações para balanço/área de controle).

Após o exame das cartas produzidas com os dados referentes à questão 166/QSL/ ALiB, são analisados os aspectos diatópicos referentes às denominações obtidas, com destaque para as unidades léxicas cartografadas.

\section{Análise diatópica das denominações para "balanço" cartografadas}

Na sequência, o exame das denominações fornecidas pelos informantes é discutido conforme a produtividade de cada variante em ordem decrescente, priorizando os dados obtidos no estado de São Paulo. 


\section{Balanço}

A unidade lexical balanço foi a mais produtiva para a pergunta 166/QSL/ALiB e foi citada por falantes de ambos os sexos e faixas etárias, em todos os pontos linguísticos investigados, com exceção de Andradina (ponto 155). Quanto à sua produtividade no estado de São Paulo, a denominação balanço teve maior número de ocorrências nas mesorregiões de Itapetininga e Metropolitana de São Paulo. Na área de controle, o item lexical balanço também foi registrado em todas as localidades pesquisadas, com pelo menos uma ocorrência.

Considerando as dimensões diassexual e diageracional, a unidade lexical balanço atingiu valores percentuais muito próximos entre os diferentes perfis: a faixa etária I (18-30 anos) indicou 83 ocorrências de balanço (53\%) contra 78 (47\%) na faixa etária II (50-65 anos). Também quanto à dimensão diassexual, os valores foram muito próximos: $51,7 \%$ do sexo feminino (85 ocorrências) e 48,3\% (76 ocorrências) do masculino proferiram a resposta balanço, como atesta o gráfico 4 :

Gráfico 4. Realização de "balanço" considerando as dimensões diassexual e diageracional

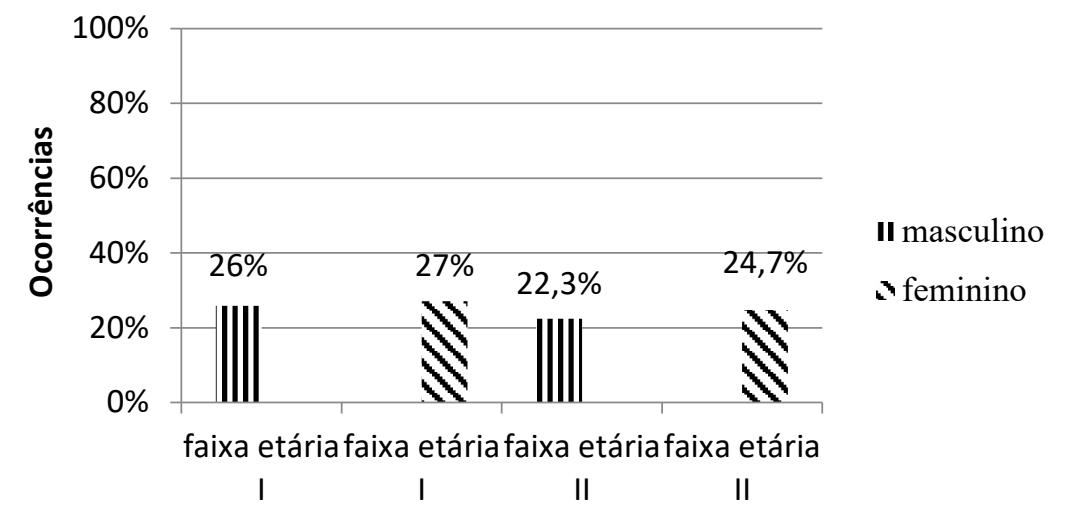

Fonte: Elaboração da autora com base no Banco de Dados do Projeto ALiB (2018)

De acordo com o gráfico 4, que indica os valores percentuais das ocorrências de balanço conforme os diferentes perfis, nota-se certo equilíbrio entre as diferentes faixas etárias e sexos da denominação balanço, predominando na fala dos informantes mais jovens $(53 \%)$ e do sexo feminino $(51,7 \%)$.

Na continuação, discutem-se os dados relativos à unidade lexical balango. 


\section{Balango}

O item léxico balango teve produtividade mais restrita, com destaque em alguns pontos do estado de São Paulo, sobretudo nas mesorregiões de: Araçatuba, Araraquara, Assis, Bauru, Marília, Presidente Prudente e São José do Rio Preto. Observando os registros de balango, nota-se que estão situados em localidades próximas a toda fronteira oeste do estado de São Paulo. Já, ao se considerar o sudoeste do estado, as ocorrências ultrapassam o território paulista, visto que as indicações de balango como resposta na área de controle estão localizadas apenas nos pontos linguísticos de Nova Londrina (207) e Tomazina (211), respectivamente, com três e uma ocorrência.

Tendo em vista os registros da unidade lexical balango, é possível delimitar uma isoléxica com essa variante, sobretudo na região Centro-Oeste do estado, pois há uma certa uniformidade nos dados no que tange às localidades em que a variante foi registrada, 0 que a diferencia dos demais pontos de inquérito do estado de São Paulo. Aparentemente, esses locais com a documentação de balango (ver carta 13a e 13b) são marcados por longa distância da capital e também por um processo de povoamento não muito antigo, destacando-se o final do século XIX e XX. No mapa do final do século XIX (Figura 1), é possível visualizar a região do Oeste/Centro-Oeste de São Paulo que era considerada um território despovoado.

Figura 1. Mapa do estado de São Paulo no final do século XIX²

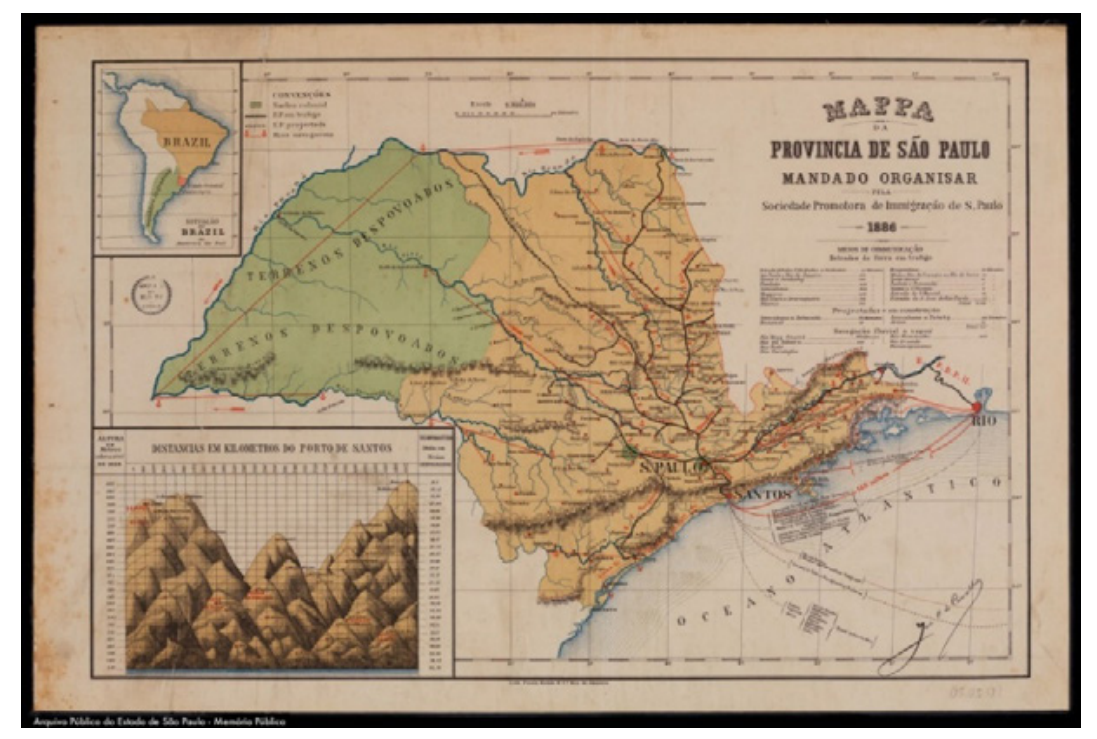

Fonte: Arquivo Nacional (2018)

2 Imagem disponível em: https://www.flickr.com/photos/arquivonacionalbrasil/376378 45541/in/ photostream/. Acesso em: 09 fev. 2018. 
Ao comparar o mapa do século XIX (Figura 1) com as localidades que registraram a variante balango (carta 13a e b), constata-se que fazem referência à mesma região, 0 que sugere que o processo de povoamento ocorreu em época próxima e também com características próprias que a distinguem de outras áreas do estado, por ser uma das primeiras em que despontou a agricultura, com a lavoura cafeeira que, além de trazer migrantes, acabou atraindo mão de obra internacional (italianos, espanhóis e japoneses) - para o trabalho na agricultura.

Em relação aos aspectos diassexuais e diageracionais, balango foi um pouco mais produtivo na fala dos informantes da faixa etária II com 15 ocorrências (52\%), enquanto entre os informantes mais jovens atingiu 14 ocorrências (48\%). Já, em relação ao sexo, é preferência na fala do informante masculino com 17 ocorrências (59\%) contra 12 (41\%) nas respostas das informantes do sexo feminino. 0 gráfico 5, a seguir, indica os valores percentuais conforme os diferentes perfis:

Gráfico 5. Produtividade da denominação balango no estado de São Paulo

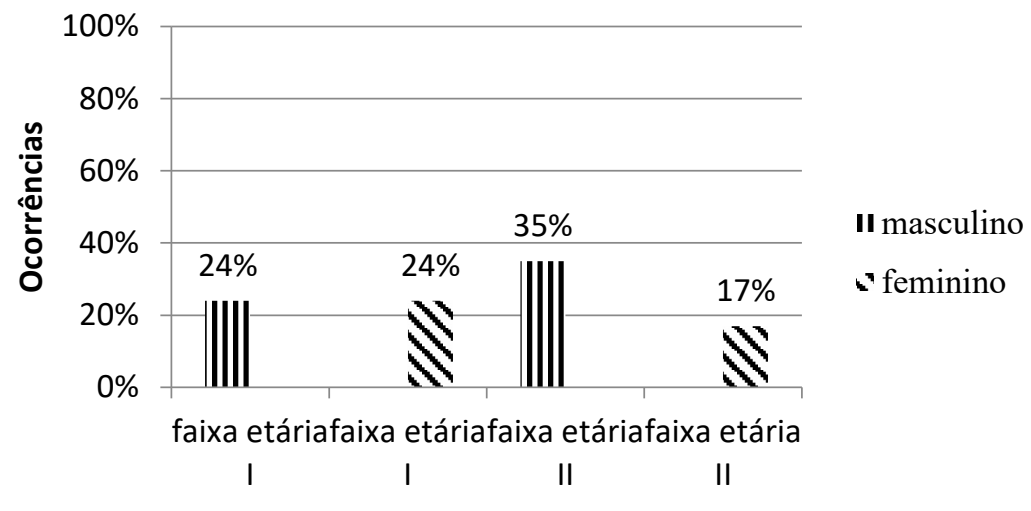

Fonte: Elaboração da autora com base no Banco de Dados do Projeto ALiB (2018)

No gráfico 5, nota-se que balango foi a denominação mais produtiva na fala dos informantes da faixa etária II (52\%) e do sexo masculino (59\%). A seguir, examina-se a disposição dos dados referentes às demais unidades léxicas produtivas.

\section{Balançador, gangorra, rede e beló}

A unidade lexical balançador foi pouco produtiva, constando apenas com quatro ocorrências, três delas documentadas no interior do estado de São Paulo, em Registro (ponto 186) e uma na área de controle, em Itajubá/MG (ponto 149). Quanto ao perfil do informante, duas ocorrências de balançador foram fornecidas por entrevistados do sexo feminino, faixa etária I e as demais foram citadas por informantes da faixa etária II, de ambos os sexos. 
A unidade lexical gangorra também foi pouco produtiva na área investigada e só foi documentada na área de controle com três ocorrências no estado de Minas Gerais: i) Campina Verde: faixa etária II, sexos masculino e feminino; ii) Passos: faixa etária II, sexo masculino. Considerando as localidades em que gangorra foi documentada e o perfil dos informantes (faixa etária II), acredita-se que a denominação gangorra tenha sido utilizada, em algum momento anterior, para denominar "uma tábua, pendurada por meio de cordas, onde uma criança se senta e se move para frente e para trás". Também não há como excluir a possibilidade de o informante ter estabelecido uma analogia com as características do brinquedo objeto da pergunta 165/QSL/ALiB como também ocorreu com a denominação daquele brinquedo ("gangorra").

Já o item lexical rede foi pouco produtivo (duas ocorrências) e foi fornecido como resposta por informantes da mesma localidade (Itapetininga - Ponto 177), respectivamente, pelo homem, faixa etária I e mulher faixa etária II. Apesar de as ocorrências terem sido registradas na mesma localidade, os falantes, muito provavelmente, estabeleceram uma analogia entre o balanço (brinquedo) e a rede (usada para descanso ou entretenimento), possivelmente em decorrência do movimento realizado pelos objetos.

De modo semelhante, a unidade lexical beló teve dois registros em municípios vizinhos (Itapetininga e Capão Bonito), ambas fornecidas por informantes do sexo masculino, faixa etária II. Em relação a essa denominação, parece ter sido um nome utilizado para designar o brinquedo em algum momento da história da região. Essa afirmação se fundamenta nos seguintes elementos: i) ter sido registrada em duas localidades próximas; ii) ter sido fornecida por informantes do mesmo perfil e iii) pela confırmação do informante de que beló denominava o brinquedo, ao ser questionado pelo inquiridor.

No que se refere aos critérios diassexuais e diageracionais das denominações com produtividade mais restrita, é possível sintetizar os dados do seguinte modo: i) rede obteve mesmo percentual de registro entre os informantes dos diferentes sexos e idades; ii) beló e balançador foram mais produtivos entre informantes de faixa etária II e iii) gangorra foi documentada apenas entre informantes da faixa etária I.

Na continuação, listam-se as denominações registradas como ocorrências únicas.

\section{Ocorrências únicas}

Os casos de ocorrências únicas foram indicados no quadro 2, a seguir, que informa a variante, a localidade/número do ponto e o perfil do informante que a menciona. 
Quadro 2. Respostas únicas para a pergunta 166/QSL/ALiB segundo a localidade e o perfil do informante (Banco de Dados do Projeto ALiB, 2018)

\begin{tabular}{|c|c|c|}
\hline Resposta única & Localidade - Ponto & Perfil do Informante \\
\hline Barquinha & Jales - ponto 150 & Mulher, faixa etária II \\
\hline Cangem & Adrianópolis - ponto 216 & Mulher, faixa etária II \\
\hline Cavalinha & Ribeira - ponto 185 & Mulher, faixa etária II \\
\hline
\end{tabular}

Fonte: Elaboração própria

Examinando o quadro 2, constata-se que todas as denominações registradas como ocorrências únicas foram citadas por mulheres da faixa etária II.

\section{Comparação com outras pesquisas geolinguísticas na área investigada}

Ao consultar os demais trabalhos dialetais produzidos na região investigada, verifica-se que poucos estudos cartografaram as denominações para "balanço". Na sequência, o quadro 3 apresenta a síntese dos dados registrados:

Quadro 3. Quadro síntese das variantes cartografadas nos atlas linguísticos

\begin{tabular}{|l|c|c|c|c|}
\hline Trabalhos/atlas & Gangorra & Balanço & Balango & Rede \\
\hline $\begin{array}{l}\text { Atlas Linguístico do Paraná II - carta 315 (ALTINO, } \\
\text { 2007, s/p). }\end{array}$ & & $X$ & & $X$ \\
\hline $\begin{array}{l}\text { Atlas Linguístico Topodinâmico do Oeste de São } \\
\text { Paulo - carta 086 (SANTOS-IKEUCHI, 2014, p. 307). }\end{array}$ & & $X$ & $X$ & \\
\hline Falar fluminense (SANTOS, 2016, p 176). & $X$ & $X$ & $X$ & \\
\hline
\end{tabular}

Fonte: Elaboração própria com base nos atlas/trabalhos referenciados

Ao observar o quadro 3, nota-se que a denominação balanço está documentada em todos os trabalhos listados. Além disso, ao consultar as cartas dos referidos atlas/trabalhos dialetais elencados, é possível afırmar que, nas três cartas assinaladas, a denominação balanço é a mais produtiva.

Na carta 315, do Atlas Linguístico do Paraná II (ALTINO, 2007), a denominação balanço foi cartografada como a resposta mais produtiva seguida de rede. Quanto aos registros de rede, informa-se que ocorrem em três regiões do estado do Paraná: i) próxima à fronteira com Santa Catarina, ii) nas imediações da área metropolitana de Curitiba/litoral e iii) próxima à fronteira do estado de São Paulo. Neste particular, destaca-se a última região listada, pois duas localidades (Guaraqueçaba- ponto 46 e Cerro Azul - ponto 37) são cidades que fazem divisa territorial com o estado de São Paulo. 
No tocante à carta 086, do Atlas Linguístico Topodinâmico do Oeste de São Paulo (SANTOS-IKEUCHI, 2014), a denominação balanço é registrada em todos os pontos de inquérito do estudo, seguido por apenas duas ocorrências de balango nas localidades de: Andradina (ponto 01) e Adamantina (ponto 02), pelos informantes do sexo masculino, faixa etária I. Como nota, a carta inclui a denominação gangorra como ocorrência única.

Por sua vez, no estudo sobre o falar fluminense (ALMEIDA, 2016), foram cartografadas as denominações: balanço (mais produtiva e registrada em todas as localidades investigadas com exceção de Pedra Azul - ponto 129), gangorra (com registros pontuais nos pontos mais ao sul do estado de Minas Gerais) e balango (nas localidades mais ao norte do estado de Minas Gerais).

Haja vista a cartografação dos dados nos trabalhos dialetais no estado de São Paulo e/ ou áreas limítrofes, nota-se que balanço é a denominação mais produtiva e concorre com as denominações balango, gangorra e rede.

Na sequência, examinam-se as variantes produtivas para "balanço" sob o viés léxicosemântico.

\section{Análise léxico-semântica}

A consulta às obras lexicográficas do século XVIII demonstraram que apenas balançar e rede estão dicionarizadas nas obras mais antigas. Em Silva Pinto (1832) e em Silva (1813), há o verbete balançar: “BALANÇAR: v. a Agitar no balanço, ou em cousa que se move como ele" (SILVA PINTO, 1832) e "BALANÇÁR: v. at. Agitar, fazer mover-se alguem no balanço, ou coisa que póde agitar-se como elle. Balançar o corpo; agitar: mas fallando das aves, se diz que balançao o corpo, quando se sostem no ar paradas, librar-se nas azas" (SILVA, 1813, p. 253), ambas as acepções permitem o estabelecimento de uma possível relação entre o brinquedo e o movimento que lhe é próprio.

Ainda entre as obras lexicográficas representativas de estágios pretéritos da língua, consta a entrada rede nos dois dicionários anteriores e também em Bluteau (1712-1728), embora não esteja definida com a acepção do brinquedo descrito na pergunta 166/QSL/ ALiB.

Entre as acepções atribuídas à unidade lexical rede, uma se destaca pela possível analogia entre o objeto descrito e o solicitado pela pergunta "Como se chama uma tábua, pendurada por meio de cordas, onde uma criança se senta e se move para frente e para trás?" (COMITÊ NACIONAL DO PROJETO ALiB, 2001, p. 36). Observe: 
7. Rede, no Brasil tecido de malha com rames, os quaes se atão nos extremos de huma vara, ou a duas argolas, e fica como huma funda, na qual se deitão a dormir, ou são levados ás costas de pretos, que sostem cada hum no hombro o extremo da tal vara, ou pão. (SILVA, 1813).

É possível que o informante tenha associado a "rede" ao "balanço", motivado pelo movimento "para frente e para trás", próprio do brinquedo. Já nas obras lexicográficas contemporâneas, foram identificadas as unidades lexicais e respectivas definições elencadas no quadro 4:

Quadro 4. Dicionarização das unidades léxicas que nomeiam o "balanço"

\begin{tabular}{|c|c|c|c|}
\hline Dicionários & Houaiss (2002) & Aulete (2006) & Ferreira (2010) \\
\hline Balanço & $\begin{array}{l}\text { "Brinquedo que } \\
\text { consiste em um } \\
\text { assento suspenso por } \\
\text { cordas ou correntes } \\
\text { fixas num suporte, } \\
\text { permitindo a realização } \\
\text { de movimentos } \\
\text { oscilatórios; balouço, } \\
\text { bambão." }\end{array}$ & $\begin{array}{l}\text { "OSCILAÇÃO; VAIVÉM: } \\
\text { Enjoou com o balanço do } \\
\text { barco. } \\
\text { Brinquedo que consiste em } \\
\text { um assento suspenso por } \\
\text { cordas ou correntes presas } \\
\text { a um suporte no alto, em } \\
\text { que a criança se senta, e } \\
\text { que oscila com o impulso do } \\
\text { corpo; BALOUÇO." }\end{array}$ & $\begin{array}{l}\text { "Aparelho que consiste } \\
\text { num assento composto } \\
\text { de travessa, tábua e } \\
\text { cadeirinha, suspenso } \\
\text { pelas extremidades por } \\
\text { cordas ou correntes, } \\
\text { onde os meninos } \\
\text { se sentam para se } \\
\text { balançarem; balouço." }\end{array}$ \\
\hline $\begin{array}{l}\text { Balango/ } \\
\text { Balangar }\end{array}$ & $\begin{array}{l}\text { "v. (1928) t.d.int. e pron. } \\
\text { Pôr(se) em balanço; } \\
\text { balançar ETIM. orig. } \\
\text { obsc. SIN/VAR ver } \\
\text { sinonímia de oscilar." }\end{array}$ & $\begin{array}{l}\text { "v. Oscilar, balançar(-se), } \\
\text { mover(-se) de um lado para } \\
\text { o outro; BALOUÇAR (-SE)." }\end{array}$ & "V.t.d., int. e p. Balançar." \\
\hline Rede & $\begin{array}{l}\text { "DESP equipamento } \\
\text { feito de rede, que se } \\
\text { estende no centro } \\
\text { da quadra de tênis, } \\
\text { voleibol etc., sobre o } \\
\text { qual a bola deve passar } \\
\text { para continuar em } \\
\text { jogo. DESP armação } \\
\text { de rede que envolve as } \\
\text { traves do gol em vários } \\
\text { esportes (futebol, } \\
\text { hóquei, handebol etc.)" }\end{array}$ & $\begin{array}{l}\text { "Têxt. Tecido de malha larga } \\
\text { e diversas finalidades, obtido } \\
\text { com o entrelaçamento de } \\
\text { fios, cordas que formam } \\
\text { retângulos, losangos e } \\
\text { outras figuras de tamanhos } \\
\text { variáveis." }\end{array}$ & \\
\hline
\end{tabular}

Fonte: Elaboração própria com base nos dados extraídos dos dicionários referenciados 
Para além dos dicionários já referenciados, consultou-se o Dicionário Etimológico Nova Fronteira (CUNHA, 1986) em que figuram apenas os itens léxicos gangorra e balanço. Quanto à gangorra, a acepção fornecida pelo dicionário faz referência ao brinquedo objeto da pergunta 165/QSL/ALiB. Já balanço é definido como: "s.m. ato ou efeito de balançar. $\mathrm{XV}^{\prime \prime}$.

Buscou-se informação no Dicionário do Folclore Brasileiro (CÂMARA CASCUDO, 2012), embora só se tenha encontrado o registro de rede com outra acepção. Por seu turno, na definição da unidade léxica rede, uma informação se destaca entre as demais: "O uso da rede, quase sempre desconhecido na Capitania de Minas ${ }^{3}$, é muito espalhado na de São Paulo, a exemplo dos hábitos dos índios, outrora numerosos nesta região" (HILAIRE apud CÂMARA CASCUDO, 2012).

Ademais dos registros dos dicionários, discutem-se também algumas possíveis motivações para as respostas obtidas. Em relação às variantes com ocorrências únicas, algumas foram fornecidas impulsionadas por diferentes razões, dentre elas, destacamse:

i) A relação estabelecida pelo informante com algum elemento do texto da pergunta, no caso, associando o movimento "para frente e para trás" com o "vai e volta":

(01) "INF. Barquinha/INQ. Barquinha? /INF. É./ INQ. Que dai vai e volta assim? INF. Vai e volta. Barquinha" (Jales - Ponto 150, informante do sexo feminino, faixa etária II).

ii) Associação a outro brinquedo ou objeto de entretenimento infantil, produzido com madeira e que a criança pode sentar e brincar, no caso o "cavalo de pau":

(02) "Aqui no parquinho é balança... tamém cavalinho lá" (Ribeira - Ponto 185, informante do sexo feminino, faixa etária II).

iii) Confırmação por parte do informante da nomeação e da classificação da variante como denominação antiga:

3 Apesar de indicar região coincidente com a deste estudo, não há descrição sobre a rede. 
(03) INF. Balanço também. Cangem também que eles diziam, antigamente, também... /INQ. Pra qual?/ INF. Era o balanço de balançar, era cangem, quando era criança diziam... vamo fazê um cangem para nós, porque o cangem vai-vem... vai-vem... de corda, às vezes fazia com um pauzinho no meio pra munta e balançá (Adrianópolis - ponto 216, informante do sexo feminino, faixa etária II).

Na sequência, são recuperados mais alguns comentários fornecidos pelos informantes acerca do uso das variantes analisadas:

i) Para alguns informantes, as perguntas 165/QSL/ALiBe 166/QSL/ALiB estão relacionadas entre si, o que acaba influenciando o fornecimento de respostas que indicam o referente da outra questão ou mesmo que marcam a diferenciação dos brinquedos:

(04) INF.- Não, aquele lá é o balango./ INQ.- Esse?/INF.- Esse é o balango./INQ.- Esse que eu tô falando, ou o outro?/INF.- Não, esse aí. Esse aí sentado, que você senta no meio, aí um vai te balangando, você vai lá longe e volta, lá longe.../ INQ.- Isso. É esse mesmo/. INF.- É, é o balango (Andradina - ponto 155, informante do sexo feminino, faixa etária I).

ii) A ocorrência da unidade lexical rede, sobretudo no caso seguinte, não parece ter sido explorada de modo a assegurar que o informante consiga se focar no brinquedo em questão:

(05) INF.- Ah, é o balanço, a rede./INQ.- Uhum!/INF.- Um balanço./ INQ.- Pode ser um balanço?/ INF.- Pode sê um balanço e pode sê rede./INQ.- E pode ser rede./INF.- Sê rede também (Itapetininga - ponto 177, informante feminino, faixa etária II).

iii) A denominação beló é confirmada a partir de questionamento do inquiridor, com vistas a apurar se a resposta fornecida pelo informante não se referia a outro objeto ${ }^{4}$.

(06) INF.- Aqui fala balanço ou beló. /INQ.- É a mesma coisa?/INF.- Mesma coisa./ INQ.- E qual que é o nome que usa mais?/INF.- Ah, mais é balanço (Capão Bonito - ponto 182, informante homem, faixa etária II).

4 Essa situação também ocorreu quando o informante indicou uma das denominações únicas (cangem), como apontado no excerto sobre as ocorrências únicas. 
(07) INQ.- Então tem um assim que pendura duas cordas, daí põe um assentozinho assim.../ INF.- Aquele é... balanço, éh... beló. Beló que eles dize./INQ.- Beló?/INF.- É./ INQ.- Vai pra frente e vai pra trás né./ INF.- Isso, vai pa frente e... (Itapetininga - ponto 177, informante masculino, faixa etária II).

De acordo com o exposto, conclui-se que, no processo de nomear o brinquedo balanço, foram consideradas como prováveis motivações tanto o movimento do "balanço" quanto o elemento tábua, comum a diferentes entretenimentos infantis e presente na pergunta selecionada.

\section{Considerações finais}

Ao analisarmos os dados obtidos para "uma tábua, pendurada por meio de cordas, onde uma criança se senta e se move para frente e para trás?" (COMITÊ NACIONAL DO PROJETO ALiB, 2001, p. 35) coletados pelo Projeto ALiB nas localidades assinaladas, percebe-se que a denominação balanço é a mais produtiva neste estudo. Além disso, pontua-se que o uso do brinquedo ainda é bastante comum e próximo da realidade dos informantes e das crianças. Essa conclusão se apoia no baixo número de não respostas, nas variantes documentadas e também nos comentários fornecidos pelos informantes.

Em relação às variantes documentadas, balanço éa forma mais produtiva e está propagada por toda a área investigada, com exceção do ponto 155 e foi registrada nas diferentes faixas etárias. Além disso, a denominação está cartografada em estudos dialetais atuais que cobrem parte da área pesquisada, com destaque no ALTOSP (SANTOS-IKEUCHI, 2014) e no falar fluminense (SANTOS, 2016), nos pontos de inquérito do estado de São Paulo, parte de Minas Gerais, litoral do estado do Rio de Janeiro e Espírito Santo. Ainda cabe destacar que a denominação balanço foi a mais produtiva nesses trabalhos geolinguísticos e no Atlas Linguístico do Paraná II (ALTINO, 2007).

No que concerne à denominação balango, obteve menor número de registros, porém figurou como uma denominação recorrente na fala dos informantes de regiões específicas do estado de São Paulo (Oeste/Noroeste/Sudoeste) o que, inclusive, marca uma possível delimitação dialetal para a variante em questão. Ademais, esse fenômeno aponta para a presença de vestígios do processo de povoamento ocorrido na região, no final do século $X I X$, que ainda se reflete no léxico local, e, consequentemente, evidencia a relação entre o léxico, a sociedade e a história social da localidade, pois o "léxico da língua é o que mais nitidamente reflete o ambiente físico e social dos falantes" (SAPIR, 1969, p. 45).

Ao considerar os estudos já concluídos na área investigada, a denominação balango foi registrada no Atlas Linguístico Topodinâmico do Oeste de São Paulo (SANTOS-IKEUCHI, 2014) e no estudo sobre o falar fluminense (SANTOS, 2016). 
No que tange à variação diassexual e diageracional, pontua-se que balanço obteve certo equilíbrio entre as diferentes faixas etárias e sexos, predominando na fala dos informantes da faixa etária I (53 \%) e do sexo feminino (51,7\%) enquanto a denominação "balango" foi mais produtiva na fala dos informantes da faixa etária II (52\%) e do sexo masculino (59\%).

Quanto às demais denominações registradas, informa-se que a variante: i) rede obteve mesmo percentual de registro entre os informantes dos diferentes sexos e idades; ii) beló e balançador foram mais produtivos entre informantes de faixa etária II; iii) gangorra foi indicada apenas entre informantes da faixa etária I e v) as ocorrências únicas foram documentadas apenas entre as informantes do sexo feminino, da faixa etária II.

Por fim, informa-se que, ao indicar denominações para o "balanço", observou-se que o movimento realizado pelo brinquedo foi fundamental para o fornecimento das respostas. Além disso, pontua-se que, no processo de nomear os brinquedos solicitados pelas questões 165 e 166/QSL/ALiB, houve certa relação de analogia entre as perguntas devido ao elemento uma tábua e ao movimento, mesmo que a descrição dos objetos fornecida pela pergunta fosse distinta.

Em síntese, a análise dos dados demonstrou que a variante balanço é a mais produtiva no corpus analisado, embora outras denominações tenham se destacado segundo as localidades em que foram registradas, como é o caso da unidade lexical balango, muito utilizada nas regiões oeste e sudoeste do estado de São Paulo, bem como nos pontos de inquéritos da área de controle pertencentes ao estado do Paraná. A documentação dessa denominação indica uma possível marca dialetal que se relaciona com fatores históricosociais das localidades assinaladas.

\section{REFERÊNCIAS}

ALTINO, F. C. Atlas Linguístico do Paraná II. 2007. 2 v. Tese (Doutorado em Estudos da Linguagem) - Centro de Comunicação e Expressão, Universidade Estadual de Londrina, Londrina, 2007.

AULETE, F. J. C.; VALENTE, A. L. dos S. Aulete Digital: Dicionário Contemporâneo de Língua Portuguesa. Rio de Janeiro: Lexikon Editora Digital, 2006. Disponível em: http://aulete.com.br/. Acesso em: 20 ago. 2018.

BIDERMAN, M. T. C. Dimensões da palavra. Filologia e Língua Portuguesa, São Paulo, Humanitas Publicações/FFLCH/USP, n. 2, p. 81-118, 1998.

BLUTEAU, R. Vocabulario portuguez \& latino: áulico, anatômico, architectonico... Coimbra: Collegio das Artes da Companhia de Jesus, 1712-1728. 
CARDOSO, S. A. M. Geolinguística: tradição e modernidade. São Paulo: Parábola, 2010.

CÂMARA CASCUDO, L. Dicionário do Folclore Brasileiro. São Paulo: Editora Global, 2012.

COMITÊ NACIONAL DO PROJETO ALiB. Atlas Linguístico do Brasil: Questionários 2001. 2 ed. Londrina: EDUEL, 2001.

COSERIU, E. Teoria da Linguagem e Linguística Geral. Rio de Janeiro: Presença Edições, 1979.

CUNHA, A. G. da. Dicionário Etimológico Nova Fronteira da Língua Portuguesa. 2. ed. Rio de Janeiro: Nova Fronteira, 1986.

FERREIRA, A. B. de H. Dicionário Aurélio da Língua Portuguesa. Curitiba: Positivo, 2010.

HOUAISS, A.; VILLAR, M. de S. Dicionário eletrônico Houaiss da Língua Portuguesa. Rio de Janeiro: Editora Objetiva, 2002. 1 CD-ROM.

SILVA, A. M. Diccionario da lingua portugueza. 2 v. Rio de Janeiro: Francisco Alves, 1922. Fac-símile da segunda edição. Lisboa: Typographia Lacérdina, 1813.

SAPIR, E. Linguística como ciência. Rio de Janeiro: Livraria Acadêmica, 1969.

SANTOS-IKEUCHI. A. C. dos. Atlas Linguístico Topodinâmico do Oeste de São Paulo. 2014. Dissertação (Mestrado em Estudos da Linguagem) - Centro de Comunicação e Expressão, Universidade Estadual de Londrina, Londrina, 2014.

SANTOS, L. A. dos. Brincando pelos caminhos do Falar Fluminense. 2016. Dissertação (Mestrado em Língua e Cultura) - Programa de Pós-Graduação em Língua e Cultura Instituto de Letras, Universidade Federal da Bahia, Salvador, 2016.

SILVA PINTO, L. M. da S. Diccionario da Lingua Brasileira por Luiz Maria da Silva Pinto, natural da Provincia de Goyaz. Na Typographia de Silva, 1832. Disponível em: http://www.brasiliana.usp.br/dicionario/edicao/1. Acesso em: 21 abr. 2017. 


\section{ANEXO 1}

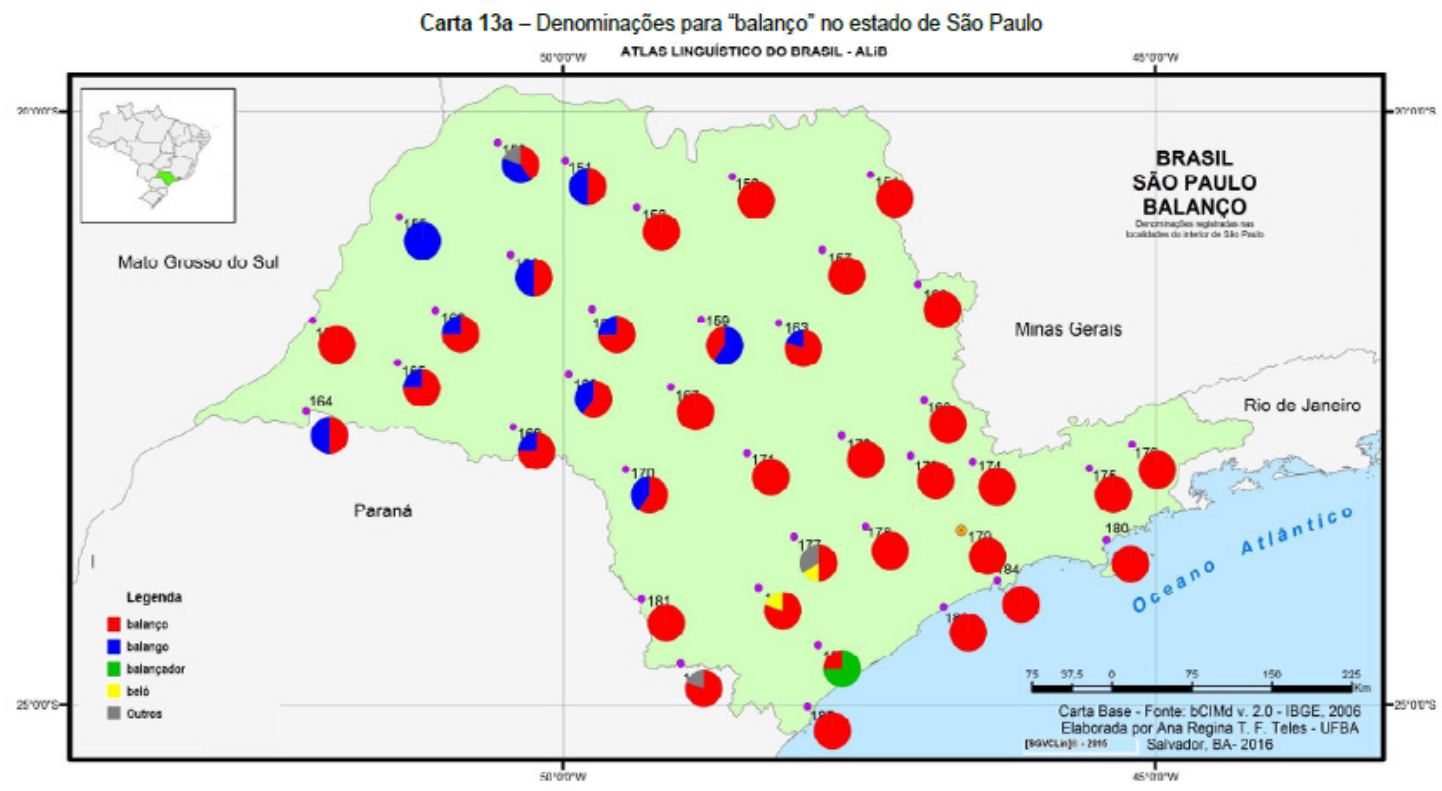

"Como se chama uma tábua, pendurada por meio de cordas, onde uma criança se senta c se move para frente c para trás?" 16G/QSLALID (COMITĹ NACIONAL DO PROJLTO ALID, 2001, p. 35)

Anállse llnguístlca e cartografla temátlca experImental: Beatriz Aparecida Alencar

Geraçäo de cartas automatizadas: SGVCLın

\section{ANEXO 2}

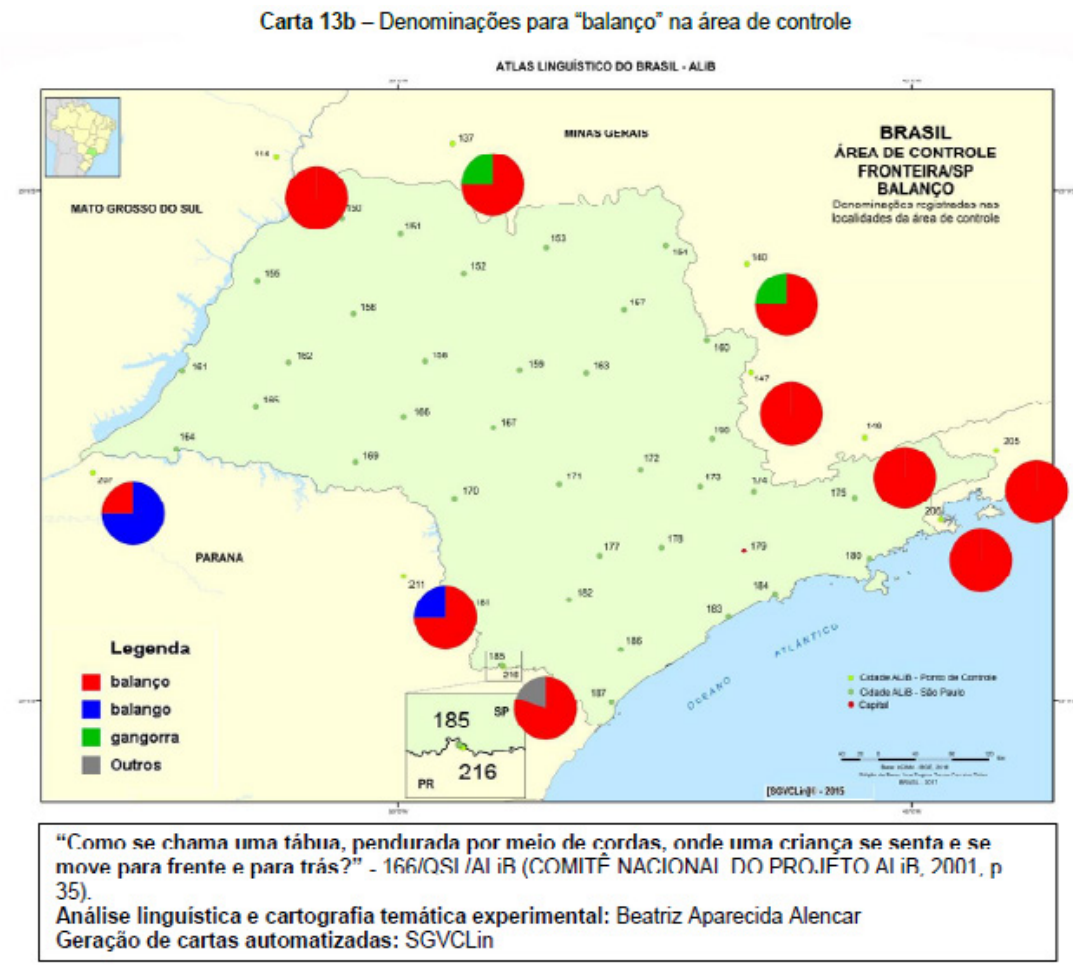

